\title{
Synthesis and Characterization of Nanosize Catalyst for the RWGS Process and Performance Examination Using a Pilot-Scale High-Pressure Reactor
}

\section{Y. K. Suneetha, Shabnam Siddiqui}

\begin{abstract}
Catalyst reduces the activation energy of molecules and is generally composed of an active part distributed on a large surfaced stable support or ligand. Since the catalytic reactions occur at the surface of the catalyst, this necessitates the method of catalysts preparation after suitable pretreatment to have an active, moderately high and accessible surface area. Also, the pretreated catalysts should have sufficient mechanical strength and stability so that the particles will remain relatively unchanged during their use as catalysts.
\end{abstract}

Nanosize metal oxide catalysts deposited on alpha-alumina are prepared using combustion synthesis in the present work. Alumina acts as support, a promoter as well as a catalyst in this process. Aluminum nitrate, cobaltous chloride, nickel chloride, ammonium molybdate, and urea are used as raw materials to synthesize cobalt-nickel-molybdenum on alumina by combustion method. The solution at $5000 \mathrm{C}$ in a muffle furnace produced voluminous solid within 5 minutes. Particle size, morphology, chemical characterization of the sample were analyzed by scanning electron microscopy (500 $\mathrm{nm}), X$-ray diffraction, and energy disperses $X$-ray analysis techniques. The results showed that the concentration of nickel among all three promoters was the least.

Increasing levels of carbon dioxide in the atmosphere have detrimental effects such as an increase in temperatures, melting of glaciers, the rise in the levels of seas and oceans, submergence of low-lying land areas and disruptions in the ecological cycles. In order to combat this, the present work was extended to convert carbon dioxide to carbon monoxide by reverse water gas shift reaction. Carbon monoxide can be later used to produce methanol and dimethyl ether which has a higher calorific value. Present process was carried out in a pilot-scale high-pressure reactor at $400{ }^{\circ} \mathrm{C}$ and 7 bar using nanoparticles of nickel-cobalt-molybdenum on alumina. Product stream was analyzed by gas chromatography with a thermal conductivity detector.

Keywords-Reverse Water Gas Shift Reaction, High-pressure Reactor, Nanocatalyst, Combustion Synthesis.

\section{INTRODUCTION}

Climate change does not respect border; it does not respect who you are-rich and poor, small and big. Therefore, this is what we call "global challenges, which require global solidarity [1]. It needs to be addressed at the earliest through collaborations between nations. One of the major causes of

Revised Manuscript Received on November 08, 2019.

* Correspondence Author

Y. K. Suneetha, Department of Chemical Engineering, B.M.S. College of Engineering, Bengaluru, Karnataka, India.

Shabnam Siddiqui, Department of Chemical Engineering, B.M.S. College of Engineering, Bengaluru, Karnataka, India. climate change is global warming, which is produced as an effect of the greenhouse effect, due to excessive concentrations of carbon dioxide in the atmosphere. When the levels of carbon dioxide in the atmosphere exceed permissible limits due to anthropogenic causes such as burning of fossil fuels etc., carbon dioxide being one of the greenhouse gases allows the small wavelength visible radiations reflected by the earth's surface to pass through it, back into space, but holds back the longer wavelength infra-red radiations reflected by the earth's surface. This trapping of longer wavelength infra-red radiations results in heating of the earth's surface.

Sea level rise, as reported by the world meteorological organization in the year 2014 indicates that the average annual sea level rise accelerated $3 \mathrm{~mm}$ worldwide, which was around double the sea level rise of $1.6 \mathrm{~mm}$ in the $20^{\text {th }}$ century. An increase also results in the absorption of the gas by oceans which increases the acidity of oceans. This would harm corals and all other aquatic life in one way or the other. Increasing temperatures would even result in the extinction of many species of flora and fauna which would not be able to adapt at the rate the climate is changing and this would lead to an imbalance in the ecosystem. There could be a loss of arable land, reduction in the levels of the water table, the combined effects of which would be crop failure, which would lead to social unrest, political instability, etc. to say the least. The world is heading towards a catastrophe, there is a need to come up with viable solutions [3].

Levels of carbon dioxide in the atmosphere can be reduced by adopting various measures. One way is to switch over to alternative and carbon-free sources of energy which include solar power, wind power, geothermal power, and nuclear power. These sources may pose an initial problem of high initial investment and some other problems, but are much more beneficial than carbon sources such as coal and oil in the long run. Also, as fossil fuels are being depleted at a rapid rate, alternative sources provide a promising venture for the future with the benefit of being eco-friendly. Another solution would be carbon capture and sequestration, wherein carbon dioxide could be removed from the atmosphere and stored [4]. The third approach is to tap the carbon dioxide present in the atmosphere and convert it into industrially important compounds such as methanol through different processes, which is the basis of our project. One of the processes available is the CAMERE (carbon dioxide hydrogenation to form methanol via a reverse water gas shift reaction) process, which is a two-step process, the first step being the 
reverse water gas shift reaction (RWGS), in which carbon dioxide reacts with hydrogen gas to produce carbon monoxide and water. $\mathrm{CO}$ produced can then be converted into methanol in the second step.

\section{RWGS PROCESS AND ANALYTICAL TOOLS}

The selectivity of the reverse water-gas shift reaction using $\mathrm{Pt} / \mathrm{TiO}_{2}$ catalyst. The CAMERE process which employs the use of the RWGS process followed by the methanol synthesis process is a promising method for the manufacture of methanol industrially. It serves to reduce the levels of carbon dioxide in the atmosphere, which helps fight global warming. A new source of raw material can be created from carbon dioxide using the hydrogenation reaction. The overall efficiency of the RWGS process and methanol synthesis was increased when these methods were used in combination, as in the CAMERE process. The high efficiency of the RWGS process can be achieved only at a high ratio of carbon dioxide to hydrogen gas, which could lead to the formation of undesirable by-products such as methane. The methane formed is undesirable for the reaction because of the reducing condition created, due to which the synthesis of methanol is negatively affected.

There is need to ensure that the catalyst employed in the RWGS process, at a high carbon dioxide-hydrogen ratio, does not generate methane and also the process is stably driven to obtain high efficiency of the methanol in the second step. The activity of $\mathrm{Pt} / \mathrm{TiO}_{2}$ catalyst was studied in the RWGS process. The parameters studied were surface characteristics and their effect on the activity and selectivity of the catalyst. Selectivity and activity of the catalyst were studied at different calcination temperatures and also at different hydrogen/carbon dioxide ratios. At higher calcination temperatures, the specific surface area of the catalyst decreased with a decrease in the activity of the catalyst. But at the particular temperature of $923 \mathrm{~K}$, there was no formation of methane, hydrogen to carbon dioxide ratio is maintained at 3:1 under these conditions. The conclusion offered for this behavior was that the selectivity of the catalyst was based upon the carbonyl species attached to the platinum sites and the formation of carbonate species on the reducible titanium dioxide sites [5].

Production of methanol was studied and compared using a two-step process as against a single step process. The single-step process is the partial oxidation of methane to yield methanol, whereas the two-step process involves the production of methanol using the RWGS process in the first step which is followed by the conversion of the carbon monoxide thus produced into methanol. The single-step process was realized to be more viable economically than the two-step process. Some of the drawbacks of the single-step process side reactions, poor selectivity and that the yield is lesser than 5\%. The paper also discusses the progress and recent advancements in order to improve the selectivity of methanol in the single-step process [6].

Preparation of methanol from $\mathrm{CO} / \mathrm{CO}_{2} / \mathrm{H}_{2}$ using $\mathrm{Cu} / \mathrm{ZnO} / \mathrm{Al}_{2} \mathrm{O}_{3}$ as catalysts and 2-butanol as the promoter is a new method at a low temperature instead of the conventional high temperature, the high-pressure process from synthesis gas using zinc oxide or copper oxide. An aqueous solution of copper nitrate and zinc nitrate was co-impregnated with

$\gamma-\mathrm{Al}_{2} \mathrm{O}_{3}$ in order to prepare the catalysts. The results obtained indicated that the yield and selectivity of methanol were the highest by using the $\mathrm{Cu} / \mathrm{ZnO} / \mathrm{Al}_{2} \mathrm{O}_{3}$ catalyst with a copper loading of $5 \%$ and the $\mathrm{Zn} / \mathrm{Cu}$ molar ratio of $1: 1$, with the precursor not being calcined and reduced at $493 \mathrm{~K}$. Increase in catalyst activity was attributed to the presence of $\mathrm{CuO} / \mathrm{ZnO}$ in oxidized form. The $\mathrm{Cu}$ sites along with the $\mathrm{Cu}-\mathrm{Zn}$ sites catalyze the reaction for methanol production[7].

Energy requirements of France are met by nuclear and renewable energy sources, thereby reducing the carbon load on the environment. This, in turn, expands the scope for hydrogen production on a large scale, but this aspect faces problems of storage as hydrogen is an inflammable gas and can lead to an explosion, if not stored properly. Instead, fuel can be produced by reacting hydrogen with carbon dioxide, with the major source for carbon dioxide being cement industries. The CAMERE process proposes promising means of achieving this objective of producing fuel from carbon dioxide and hydrogen through a two-step process. The methanol produced can be further converted into dimethyl ether, which can be used as a potential fuel. In this paper, the production of DME was studied by using monoethanolamine solution for carbon dioxide absorption and hydrogen was produced by electrolysis of alkaline water. The hydrogen and carbon dioxide on reaction led to the formation of methanol which was further converted into DME[8].

The review has been carried out to understand the effects of carbon dioxide and problems encountered during methanol production. Copper, zinc, chromium, and palladium are some of the most commonly used catalysts [9]

RWGS reaction is important primarily to mitigate a large quantity of greenhouse gas (GHG) emissions by catalytic hydrogenation of $\mathrm{CO}_{2}$ to $\mathrm{CO}$ thereby producing methanol which is consumed in the conventional chemical industry and dimethyl carbonate (DMC - a clean fuel). Impregnation method in catalyst synthesis is used instead of an alternative precipitation method which enhances the selectivity of $\mathrm{CO}$ in RWGS. Two catalysts $\left(\mathrm{Mo} / \mathrm{Al}_{2} \mathrm{O}_{3}\right.$ and $\left.\mathrm{Co}-\mathrm{Mo} / \mathrm{Al}_{2} \mathrm{O}_{3}\right)$ are compared for their activity and co selectivity in RWGS reaction taking place in a batch reactor. The catalyst which performed better in its activity is proposed to CAMERE process. Catalyst structures were studied using XRD, XRF and team techniques. $\mathrm{Co}-\mathrm{Mo} / \mathrm{Al}_{2} \mathrm{O}_{3}$ showed higher activity than $\mathrm{Mo} / \mathrm{Al}_{2} \mathrm{O}_{3}$ catalyst and has an overall higher $\mathrm{CO}$ selectivity. Cobalt, when added as a promoter, proved to increase the activity and hence it is suitable for RWGS reaction and CAMERE process [10].

The future of GHG emissions will be impacted by the critical action of the largest emitters (developed countries) who must step up and invest in the advanced ccs technology to avoid blame for our deteriorating mother earth. Increase in $\mathrm{CO}_{2}$ emissions is linked to fast economic development in large countries like China and India with an increasing world population. CCS offers an emergent solution and gives us more time to transit energy systems towards sustainable energy sources. Stored carbon can be used in the long run as a regulator for global temperature. The safe proposed level for $\mathrm{CO}_{2}$ concentration in the atmosphere is estimated to be below $350 \mathrm{ppm}$ which must be striven for [11]. 


\subsection{Catalyst preparation methods}

Fresh HDS catalysts are commercially available in oxide form. Catalysts are generally prepared by maceration, homogenous sulfide precipitation (HSP), mixed metal salts or organometallic clusters decomposition by combustion or impregnation of binary sulfides methods. Most of these techniques developed for the synthesis of $\mathrm{Co} / \mathrm{Mo}$ or $\mathrm{Ni} / \mathrm{Mo}$ catalysts are applicable to other systems. The Comaceration method consists of freshly prepared oxides with a solution of ammonium sulfide at moderate temperature $\left(\sim 70^{\circ} \mathrm{C}\right)$. The slurry is continuously stirred until evaporation to dryness. The catalysts are obtained by thermal treatment under vacuum.

The HSP corresponds to a low-temperature co-precipitation. In this case, two or more salts are dissolved prior to the addition of a sulfiding agent. The synthesis of unsupported Co-Mo sulfide provides a good example of HSP method: A solution of cobalt nitrate and ammonium heptamolybdate is poured into a hot solution of ammonium sulfide. The slurry is then evaporated to dryness.

Thermal decomposition of molecular metal-sulfur complexes was studied, either starting from salts where both the anion and cation contain one of the metals or starting from molecular complexes in which two metals are a part of same molecular sulfur-ligated clusters at the outset. $\mathrm{Co}(\mathrm{en})_{3} \mathrm{MoS}_{4}$ and $\mathrm{Co} / \mathrm{Mo}$ cube are examples of precursors. These can then decompose under different conditions such as inert atmosphere, hydrogen, $\mathrm{H}_{2} \mathrm{~S} / \mathrm{H}_{2}$ or in situ. The second metal, for example, the promoter, may also be added by subsequent impregnation of binary sulfide. Non-reactive promoter precursor, for example, metal nitrate, is used. The oxide catalysts are prepared by impregnation of the alumina supported with $\mathrm{Co}, \mathrm{Ni}$, and Mo. These materials decomposed during the drying and calcination, which follow the impregnation step and their decomposition products are removed. The fresh oxide catalyst consists of well-dispersed
$\mathrm{CoO}, \mathrm{NiO}$ and $\mathrm{MoO}_{3}$ on alumina. $\mathrm{Mo}$ is bonded to the alumina support through Mo-O-Al linkages.

\section{MATERIALS AND METHODS}

\subsection{Combustion synthesis}

Muffle furnace is used for combustion synthesis. Muffle has a rectangular cross-section and dimension of 11.3 " $\times 22^{\text {" }} \times 18.6$ " with a temperature controller. The outside wall of the muffle furnace is made of mild steel and inside is brick-lined. The reactor has a feature of heating range from $100^{\circ} \mathrm{C}$ to $1200^{\circ} \mathrm{C}$. Chamber offers 120 or $350 \mathrm{in}^{3}$ of heating space the energy efficiency is enhanced through the use of high thermal efficient ceramic insulation surrounding the chamber.

Clear solutions of the calculated amount of the reagents are prepared separately and are taken in a borosilicate dish of 130 $\mathrm{cm}^{3}$. The dish is placed in the furnace which is maintained at $500^{\circ} \mathrm{C}$, the solution boils thus dehydrating followed by frothing and foaming later ignites with a blue flame. The sample is allowed to cool after combustion and cooling.

Chemicals used for the work are urea, cobaltous chloride, nickel chloride, sodium hydroxide, aluminum nitrate, ammonium molybdate and are of LR grade with distilled water.

3.2 High-pressure catalytic reactor system: The High-Pressure reactor system (Xytel) shown in Figure 3.1 includes a high-pressure gas feed system, a liquid feed module, a reactor assembly, and a gas-liquid separation system. The system can be operated at $600^{\circ} \mathrm{C}$ (maximum) temperature and up to 50 bar gauge (maximum) pressure. The system will incorporate active safeguards to ensure safe operation. The control system is a single loop controller based system. The piping and instrumentation of the reactor system are shown in Figure 3.2.

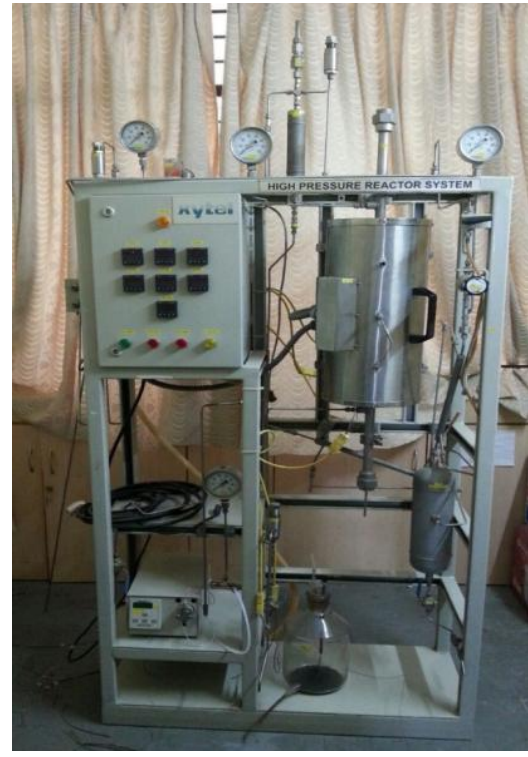

Figure 3.1: High-pressure Reactor Setup

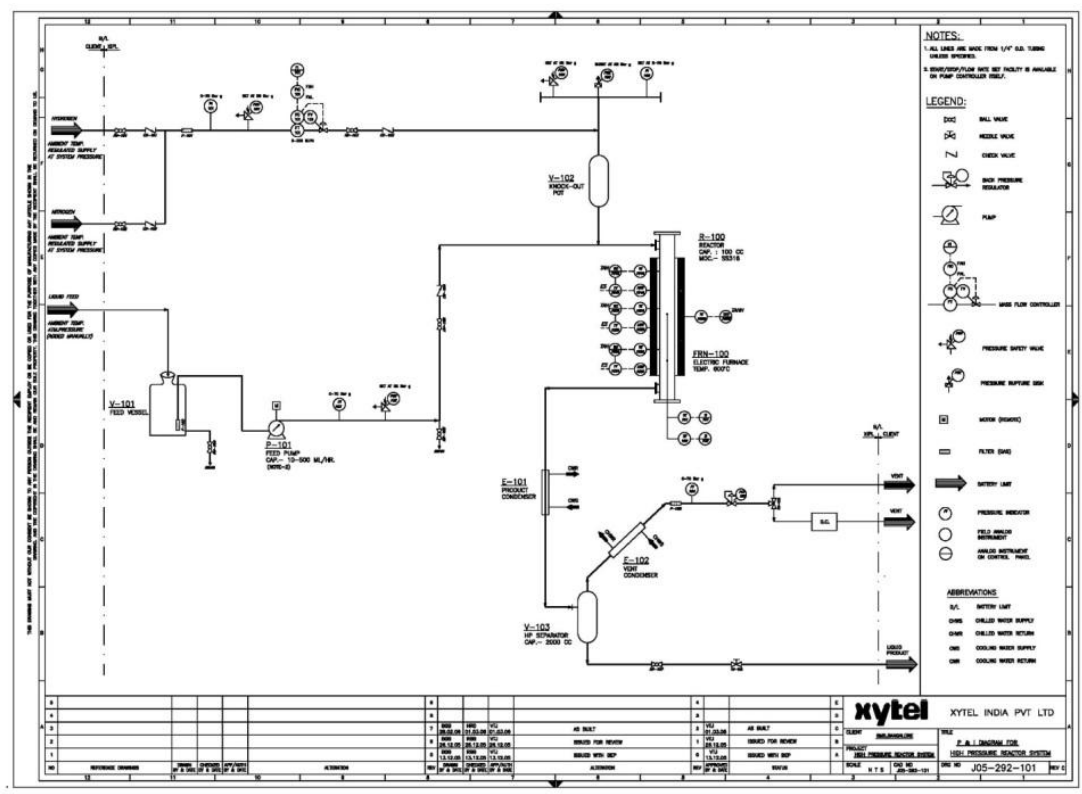

Figure 3.2: Piping and Instrumentation Drawing for High Pressure Reactor System
The high-pressure gas feed module:

Hydrogen: The function of this module is to deliver hydrogen at constant flow rates into the system at pressure up to 50 bar (gauge). Hydrogen is provided at constant and accurately metered flow rates. The self-contained mass flow controller consists of a mass flow meter (FT), flow controller (FIC), and control valve (FV). 
The flow transducer measures the flow based on thermodynamic principles which eliminate the need to correct the flow values for changing temperature and pressure conditions. The flow control valve (FV), which is an integral part of the mass flow controller, regulates the gas flow using a setpoint signal from the controller and a mass flow signal from the sensor. The mass flow controller is capable of delivering hydrogen in the range of 6-300 SLPH. The gas feed system also includes pressure gauges, manual valves, and an isolation check valve to prevent contamination.

High-pressure nitrogen module: Nitrogen is used for purging and pressure testing. The mass flow controller available on the hydrogen line should be used for feeding nitrogen to the system for purging as well as a pressure test. This gas feed system also includes isolation valves and check valves to prevent contamination from the other streams.

Liquid feed module: Provision for liquid feed storage in feed vessel (V-101) and also for pumping into the reactor using a feed pump with necessary filters, isolation valves, and pressure gauges is available. The feed pump is an HPLC type metering pump with a maximum flow capacity of 6-600 mL/h equipped with inbuilt speed controller and keypad for changing the flow rate. The diesel feed at the outlet of the pump is mixed with hydrogen before entering the reactor.

Reactor module: Reactor system is configured such that the flow through the reactor can be in downward mode through the catalyst bed. Reactor capacity is $35 \mathrm{cc}$. The MOC of the reactor is SS 316. The reactor is designed for a maximum operating pressure of 50 bar gauge and maximum operating temperature of $650^{\circ} \mathrm{C}$. The reactants enter and exit through the socket welded nozzles.

The reactor has a vertical thermowell in the middle along the reactor length containing two thermocouples to measure catalyst bed temperature at two different locations along the length of the reactor. The reactor furnace (FRN-100) is a split-type isothermal three-zone furnace. It has a pre-heat and a post-heat zone at the top and bottom. The wattage of the preheat zone will be such that the feed vapor temperature at the exit of the preheat zone will be the reaction temperature for the entire feed range. The reactor skin temperature is measured at three points. Each zone of the furnace has a thermocouple mounted on the outside of the reactor along with the controller to control the temperature of that zone. Also, the catalyst zone of the furnace has a dedicated analog temperature safety switch (TSS). A pressure gauge is provided on the reactor inlet line to know the inlet pressure to the reactor. A high-pressure safety valve and a ruptured disc are provided at the top of the reactor for safety purpose.

Gas/liquid separation and product recovery: The product stream is cooled by a water-cooled condenser (E-101) and passed through a high-pressure separator $(\mathrm{V}-103)$. The High-pressure separator will act as a collection vessel. The liquid product has to drain manually after a periodic interval. The high-pressure separator exit gas is passed through a filter. System pressure is controlled by using a back pressure regulator installed on the gas line. The system pressure is to be set manually by turning the knob clockwise or anticlockwise. Instrumentation: The high-pressure reactor system is equipped with all necessary instrumentation on all vital points in order to control, monitor and collect data wherever necessary. The system instrumentation hardware is specified for the safe area classification as in case of pilot plants.
Control system: The plant operation, control, and safety management of the unit are done by microprocessor-based stand-alone, panel-mounted controllers. The control system consists of microprocessor-based single loop controllers and indicators mounted on an IBX facilitating local indication. Process values are continuously displayed on the controllers. Further, the values of setpoint, auto/manual selection, direct/reverse action and tuning parameters can be changed using the keys available on the controllers. The IBX also houses other instruments such as relays, power supplies, fuses, contractors, etc. Incoming isolator with necessary voltmeter/ammeter is in NCL's scope of supply. Remaining switchgear (MCBs, fuses, contactors, etc.) shall be in our scope of supply.

Design specifications: The high-pressure reactor system is designed based on the specifications. Specifications are Reactor maximum temperature of $600^{\circ} \mathrm{C}$; The operating pressure up to 50 bar gauge, Hydrogen flow rate of 6-300 SLPH, and liquid flow rate of 6-600 mL.h.

\subsection{General specifications}

Materials of construction: Reactor material, process tubing handling process liquid, vessels, and equipment handling process liquid are made of SS316.Utility and instrument air tubing is brass. Vent header is carbon steel. Sealing materials used are nylon, Teflon or other compatible materials.

Pre-start-up checklist: Pre-start-up checklist includes a list of activities to be performed before start-up. The following activities are completed before the start-up of the plant. Gases required are hydrogen, nitrogen and carbon dioxide. Nitrogen is initially used for the pressure test. Close valve (HV-102) and open valve (HV-101). The furnace was ensured to be closed properly at the starting of the process. Cooling water supply was given to product condenser and vent condenser. High-pressure separator (V-103) was made empty. The three-way valve (HV-109) was diverted towards the vent.

Catalyst loading: The bed thermocouple adapters were removed by loosening it. The inlet and outlet tubing of the furnace was disconnected. The reactor was removed from the furnace. The reactor was dissembled and cleaned. A predetermined quantity of catalyst \& inert is filled into the reactor. Top fitting of the reactor was fixed. The reactor was installed in the furnace and the furnace was closed. Inlet and outlet tubing of the reactor was connected. Thermocouples fixed to the bed were connected into the thermocouple adapters.

Pressure test: To ensure that the reactor nozzle and reactor end connections are leak-free, a pressure test is necessary after loading the reactor. Pressurization was carried out by passing nitrogen through a mass flow controller for slow pressurization of the system. The system pressure was set by positioning the backpressure regulator. It was incremented in steps so that leakages can be found out at lower pressures and fixed. Soap test was conducted and no leakages were detected. Pressure drop was observed which should not exceed the pressure of 2 bar in $12 \mathrm{~h}$. If the pressure drop exceeded 2 bar in $12 \mathrm{~h}$, then the leakage has to be identified by soap solution/gas detector. Most probable leaking joints are at the reactor inlet/outlet connections; reactor end fittings and isolation valves of MFC. The system was depressurized slowly, after the pressure test. 


\section{RESULTS AND DISCUSSION}

Research work includes preparation of the catalyst, characterization of the catalyst and conduction of RWGS process.

4.1 Alumina synthesis: The combustion mixture for the preparation of $3 \% \mathrm{Al}_{2} \mathrm{O}_{3}$ contained $\mathrm{Al}\left(\mathrm{NO}_{3}\right)_{3}$ and $\mathrm{NH}_{2} \mathrm{CONH}_{2}$ in the mole ratio $0.66: 1.65$. In a typical preparation, $8.5 \mathrm{~g}$ of $\mathrm{Al}\left(\mathrm{NO}_{3}\right)_{2}$ and $3.4 \mathrm{~g}$ of urea was dissolved in $8 \mathrm{~mL}$ of water in a borosilicate dish of $130 \mathrm{~cm}^{3}$ capacity then the dish containing redox mixture was introduced into the muffle furnace maintained at $500{ }^{\circ} \mathrm{C}$. Initially, the solution boiled with frothing and foaming and underwent dehydration at the point of complete dehydration the surface foam ignited burning with the flame (approx. $1500^{\circ} \mathrm{C}$ ) and yielding a voluminous solid within 5 minutes. The combustion reaction is represented as

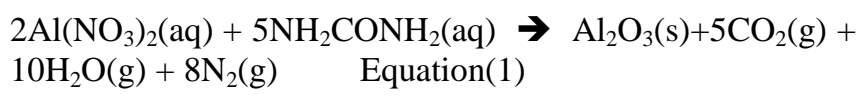

4.2 Cobalt-Nickel-Molybdenum Synthesis: Combustion mixture for the preparation of $3 \%$ catalyst contained $\mathrm{Al}_{2}\left(\mathrm{NO}_{3}\right)_{3}, \mathrm{CoCl}_{2}, \mathrm{NiCl}_{2},\left(\mathrm{NH}_{4}\right)_{6} \mathrm{Mo}_{7} \mathrm{O}_{24}$ and $\mathrm{NH}_{2} \mathrm{CONH}_{2}$ in the mole ratio 0.66:0.02:1.65. In a typical preparation $25.5 \mathrm{~g}$ of $\mathrm{Al}_{2}\left(\mathrm{NO}_{3}\right)_{3}, 0.21 \mathrm{~g}$ of $\mathrm{NiCl}_{2}, 0.21 \mathrm{~g}$ of $\mathrm{CoCl}_{2}, 1.08 \mathrm{~g}$ of $\left(\mathrm{NH}_{4}\right)_{6} \mathrm{Mo}_{7} \mathrm{O}_{24}$ and $10.2 \mathrm{~g}$ of $\mathrm{NH}_{2} \mathrm{CONH}_{2}$ was dissolved in 30 $\mathrm{mL}$ of water in a borosilicate dish of $130 \mathrm{~cm}^{3}$ capacity then the dish containing redox mixture was introduced into the muffle furnace maintained at $500^{\circ} \mathrm{C}$. Initially, the solution boiled with frothing and foaming and underwent dehydration at the point of complete dehydration the surface foam ignited burning with the flame (approx. $1500^{\circ} \mathrm{C}$ ) and yielding a voluminous solid within $5 \mathrm{~min}$. The reaction is represented as

$$
\begin{gathered}
\left(\mathrm{NH}_{4}\right)_{6} \mathrm{Mo}_{7} \mathrm{O}_{24} \cdot 4 \mathrm{H}_{2} \mathrm{O}+\mathrm{NiCl}_{2} \cdot 6 \mathrm{H}_{2} \mathrm{O}+\mathrm{CoCl}_{2} \cdot 6 \mathrm{H}_{2} \mathrm{O} \rightarrow 7 \mathrm{Mo}+\mathrm{Ni}+\mathrm{Co}+6 \mathrm{~N}_{2}+ \\
12 \mathrm{H}_{2}+2 \mathrm{Cl}_{2}+16 \mathrm{H}_{2} \mathrm{O}+12 \mathrm{O}_{2}
\end{gathered}
$$

4.3 Determination of density of catalyst sample: A specific quantity of catalyst sample is taken in a petri dish and the weight of the catalyst is measured. Later the catalyst is

Table 4.1: Density of Co-Mo $/ \mathrm{Al}_{2} \mathrm{O}_{3}$ (average density value of $0.8088 \mathrm{~g} / \mathrm{cc}$ )

\begin{tabular}{|l|l|l|l|}
\hline & Mass, g & Volume, cc & Density, g/cc \\
\hline Trial 1 & 1.5663 & 2.0 & 0.7832 \\
\hline Trial 2 & 1.5939 & 2.0 & 0.7969 \\
\hline Trial 3 & 1.6930 & 2.0 & 0.8465 \\
\hline
\end{tabular}

The ratio of mass to the volume will give the density of the catalyst sample. Three trials (Table 4.1) are made and the average of all the trial is taken as the density of the catalyst sample. poured into a measuring cylinder, tap to get uniform packing of particles and the tap density is measured.

Table 4.2: Density of Co-Ni-Mo/Al $\mathrm{O}_{2} \mathrm{O}_{3}$ (an average value of $0.5005 \mathrm{~g} / \mathrm{cc}$ )

\begin{tabular}{|c|c|c|c|}
\hline & Mass, g & Volume, cc & Density, g/cc \\
\hline Trial 1 & 1.0012 & 2.0 & 0.5006 \\
\hline Trial 2 & 1.0001 & 2.0 & 0.5000 \\
\hline Trial 3 & 1.0021 & 2.0 & 0.5010 \\
\hline
\end{tabular}

4.4 Characterization of the catalyst using SEM, XRD, EDAX and gas analysis using Gas Chromatography

Synthesized catalyst was characterized. The SEM images of the catalysts obtained are shown in Figure 4.1 and Figure 4.2. XRD spectrum of catalyst is shown in Figure 4.3. The particles are of micron size, elements of the sample are reported in Table 4.4 and 4.5. FTIR report of the catalyst composition is reported in Figure 4.4 and 4.5.

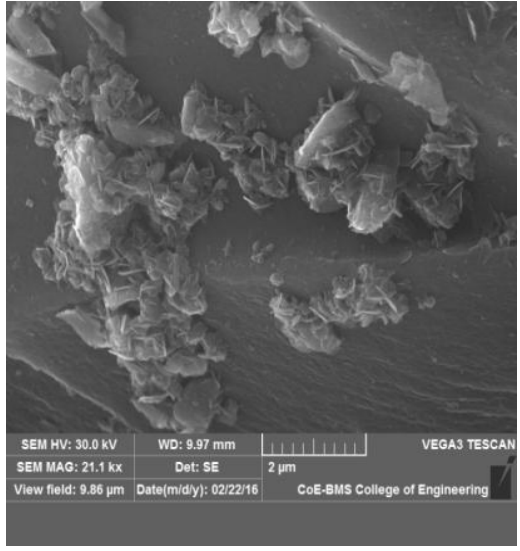

Figure 4.1: Morphology of $\mathrm{Co}-\mathrm{Mo} / \mathrm{Al}_{2} \mathrm{O}_{3}$ catalyst by Scanning Electron Microscope

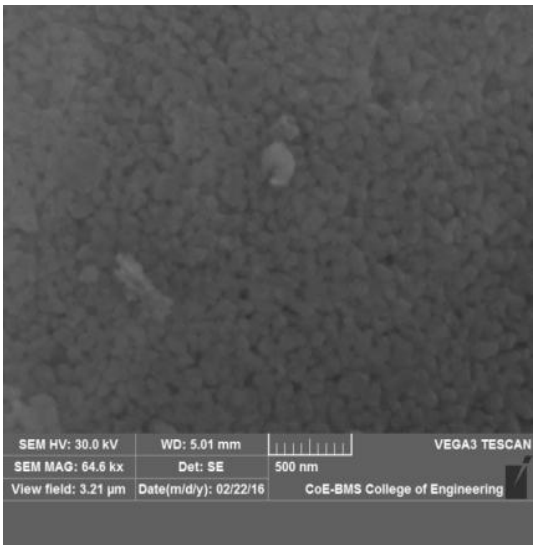

Figure 4.2: Morphology of $\mathrm{Co}-\mathrm{Ni}-\mathrm{Mo} / \mathrm{Al}_{2} \mathrm{O}_{3}$ catalyst by Scanning Electron Microscope

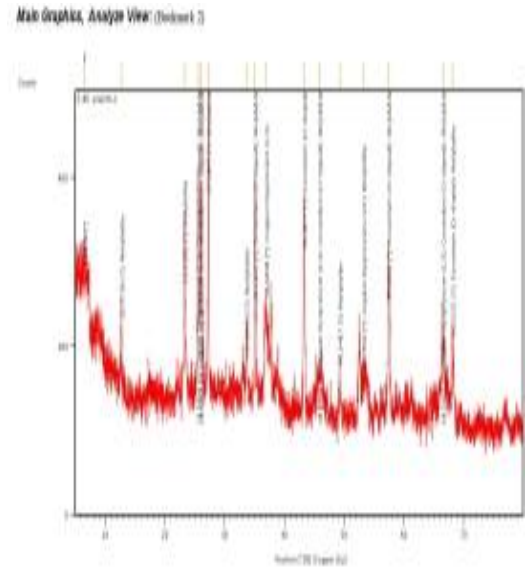

Figure 4.3: XRD spectrum of $\mathrm{Co}-\mathrm{Ni}-\mathrm{Mo} / \mathrm{Al}_{2} \mathrm{O}_{3}$ 


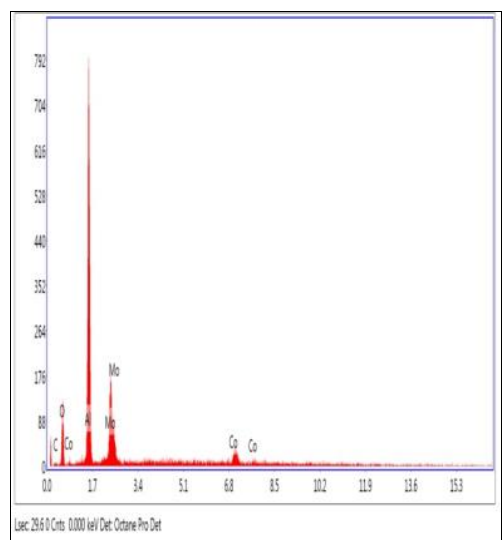

Figure 4.4: $\mathrm{Co}-\mathrm{Mo} / \mathrm{Al}_{2} \mathrm{O}_{3}$ catalyst analysis by FTIR

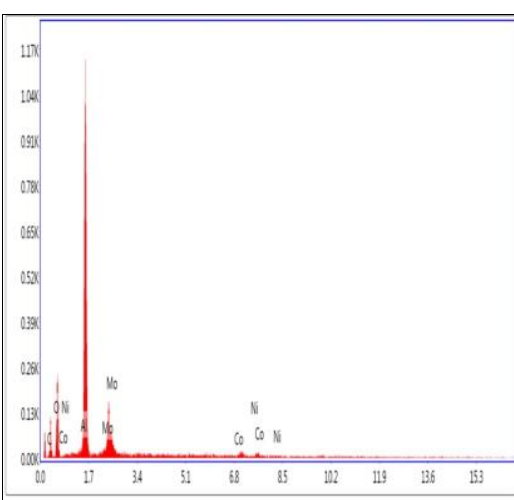

Figure 4.5: $\mathrm{Co}-\mathrm{Ni}-\mathrm{Mo} / \mathrm{Al}_{2} \mathrm{O}_{3}$ catalyst analysis by FTIR

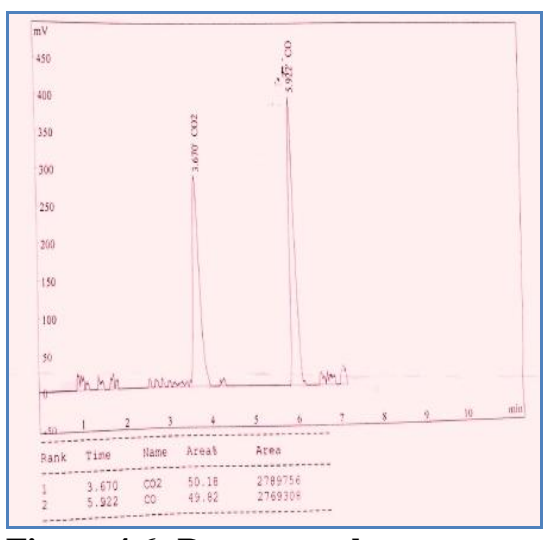

Figure 4.6: Reactor outlet gas analysis by gas chromatography
The catalyst can be used directly as such in powdered form with glass wool at the top and bottom of the

Table 4.3: FTIR report of $\mathrm{Co}-\mathrm{Ni}-\mathrm{Mo} / \mathrm{Al}_{2} \mathrm{O}_{3}$

\begin{tabular}{|c|c|c|c|}
\hline Element & Weight \% & Atomic $\%$ & Net Int. \\
\hline C K & 34.73 & 47.51 & 12.40 \\
\hline O K & 37.04 & 38.03 & 27.07 \\
\hline Al K & 20.85 & 12.70 & 105.44 \\
\hline Mo L & 2.79 & 0.48 & 7.82 \\
\hline Co K & 3.40 & 0.95 & 8.46 \\
\hline Ni K & 1.19 & 0.33 & 2.78 \\
\hline
\end{tabular}

Percentages of $\mathrm{Co}, \mathrm{Mo}$, and $\mathrm{Ni}$ are least compared to $\mathrm{Al}$ as shown in Figure 4.4 and 4.5. 99.99\% pure carbon dioxide and hydrogen were the reactants sent to the reactor for the RWGS process. The reactor outlet gas was analyzed for the composition using gas chromatography and reported in Figure 4.5.

Future scope: Study on different components of the catalyst to increase $\mathrm{Ni}$, Co and Mo percentages, reactivation of the catalyst, RWGS reaction at various temperature and pressure, conversion of $\mathrm{CO}$ to methanol using the same facility can be carried out. Activation of the catalyst with promoters and followed by characterization can be worked on. Reaction kinetics of catalyst preparation and the catalytic reaction can be studied using UNISIM software and modeled.

\section{CONCLUSIONS}

Catalysts for the RWGS process were synthesized and characterized. Particles of catalyst composite have low metal oxide concentration. $\mathrm{CO}_{2}$ is converted into $\mathrm{CO}$ using $\mathrm{Ni}-\mathrm{Co}-\mathrm{Mo} / \mathrm{Al}_{2} \mathrm{O}_{3}$ at a temperature of $400^{\circ} \mathrm{C}$ and pressure of 7 bar. About $60 \%$ conversion of carbon dioxide to carbon monoxide is achieved. This is attributed to low $\mathrm{Ni}, \mathrm{Co}$, and Mo concentration.

\section{ACKNOWLEDGMENTS}

Author is grateful to the management of B.M.S. College of Engineering for providing the facilities for conduction of the research, AICTE-TAPTEC for funding towards the research work. The author also thanks the Center of Excellence at BMSCE for characterization facility. The author expresses sincere thanks to TEQIP II, and TEQIP III at B.M.S. College reactor to avoid entrainment of particles with product stream and as support respectively.

Table 4.4: FTIR report of $\mathrm{Co}-\mathrm{Mo} / \mathrm{Al}_{2} \mathrm{O}_{3}$

\begin{tabular}{|c|c|c|c|}
\hline Element & Weight $\%$ & Atomic $\%$ & Net Int. \\
\hline $\mathrm{C} \mathrm{K}$ & 9.75 & 18.38 & 1.54 \\
\hline $\mathrm{O} \mathrm{K}$ & 30.93 & 43.74 & 19.21 \\
\hline $\mathrm{Al} \mathrm{K}$ & 35.93 & 30.14 & 107.60 \\
\hline $\mathrm{Mo} \mathrm{L}$ & 8.37 & 1.97 & 13.14 \\
\hline Co K & 15.01 & 5.77 & 23.91 \\
\hline
\end{tabular}

of Engineering for providing financial support for the successful completion of the research project.

\section{REFERENCES}

1. http://www.brainyquote.com/quotes/keywords/climate_change.html.

2. http://www.preservearticles.com/201101032332/harmful-effects-of-c arbon-dioxide.html.

3. http://www.livescience.com/37057-global-warming-effects.html.

4. http://teeic.indianaffairs.gov/er/carbon/carboninfo/reduce/index.html.

5. Kim S.S., Park K.H., and HongS.C., 'A study of the selectivity of the reverse-water-gas-shift reaction over $\mathrm{Pt} / \mathrm{TiO}_{2}$ catalysts', Fuel Process Techno., Vol.108, 2013, pp 47-54.

6. Khirsariya P. and Raju K.M., 'Single-step oxidation of methane to methanol-towards better understanding', Procedia Engg., Vol.51, 2013, pp 409-415.

7. Yang R., Yu X., Zhang Y., Wenze Li, and Noritatsu Tsubaki,' A new method of low-temperature methanol synthesis on $\mathrm{Cu} / \mathrm{ZnO} / \mathrm{Al}_{2} \mathrm{O}_{3}$ catalysts from $\mathrm{CO} / \mathrm{CO}_{2} / \mathrm{H}_{2}$ ', Fuel, Vol. 87, 2008, pp 443-450.

8. Vibhatavata P., Borgard J.M., Tabarant M., Bianchi D., and Mansilla C., 'Chemical recycling of carbon dioxide emissions from a cement plant into dimethyl ether, a case study of an integrated process in France using a reverse water gas shift (RWGS) step', Int. J. Hydrogen Energy, Vol. 38, 2013, pp. 6397-6405.

9. Jadhav S.G., Vaidyaa P.D., Bhanage B.M., and Joshi J.B., 'Catalytic carbon dioxide hydrogenation to methanol: A review of recent studies', Chem. Engg. Res. Des., Vol. 92, 2014, pp. 2557-2567.

10. A. Gharibi Kharaji and A. Shariati, 'Performance of $\mathrm{Co}-\mathrm{Mo} / \mathrm{Al}_{2} \mathrm{O}_{3}$ nanocatalyst for CAMERE process in a batch reactor' Chem. Biochem. Engg. Q., Vol. 27 (3), 2013, pp. 275-278.

11. Wennersten R., Sun Q. and Li H., "The future potential for carbon capture and storage in climate change mitigation - an overview from perspectives of technology, economy, and risk", J. Cleaner Prod., 2014, pp. 1-13. 